\title{
Prevalence of $\Delta F 508$, G551D, G542X, and R553X mutations among cystic fibrosis patients in the North of Brazil
}

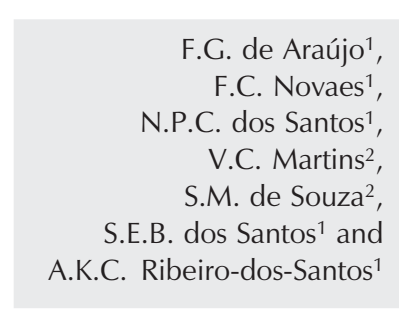

\author{
'Laboratório de Genética Humana e Médica, Departamento de Patologia, \\ Centro de Ciências Biológicas, Universidade Federal do Pará, Belém, PA, Brasil \\ ${ }^{2}$ Hospital Universitário João de Barros Barreto, Universidade Federal do Pará, \\ Belém, PA, Brasil
}

Correspondence

A.K.C. Ribeiro-dos-Santos

Laboratório de Genética Humana

e Médica

Departamento de Patologia

Centro de Ciências Biológicas, UFPA

Caixa Postal 8615

66075-970 Belém, PA

Brasil

Fax: +55-91-249-0373

E-mail: andrea@canal13.com.br or akely@ufpa.br

Received October 31, 2003 Accepted October 19, 2004

\begin{abstract}
Cystic fibrosis (CF) is the most common genetic disease among Caucasians and is rare among sub-Saharan Africans. The Brazilian population is not ethnically homogeneous but it is the result of threeway ethnic admixture of Europeans, Africans and Amerindians in varying proportions, depending on the region. In the present study, we investigated 33 patients who had been diagnosed and are currently under treatment for $\mathrm{CF}$ at the University Hospital João de Barros Barreto, Belém, Pará State. The molecular analysis for G542X, G551D and R553X mutations was performed by PCR followed by RFLP using BstNI, HincII and $M b o$ I, respectively, in polyacrylamide gel eletrophoresis and stained with $\mathrm{AgNO}_{3}$. The $\Delta \mathrm{F} 508$ mutation (a deletion of $3 \mathrm{bp}$ ) was only analyzed by polyacrylamide gel electrophoresis and stained with $\mathrm{AgNO}_{3}$. Each sample was analyzed for regions of interest in the CFTR gene using amplified by PCR and specific primers. The $\Delta \mathrm{F} 508$ and G551D mutations presented frequencies of 22.7 and $3 \%$, respectively. In $74.3 \%$ of the remaining patients, none of the mutations investigated was found. The present study characterized in a sample of patients with an established clinical diagnosis of CF (asthma, repeated bronchopneumonia, disorders of nutritional status, etc.) the most frequent mutation $(\Delta \mathrm{F} 508)$ in the North region of Brazil and is also the first report of the G551D mutation. In spite of the wide spectrum of CF mutations and the heterogeneous ethnic origin of the Amazon population, the molecular diagnosis is a helpful additional tool for the diagnosis and treatment of CF patients.
\end{abstract}

Cystic fibrosis (CF) is an exocrine disease with an autosomal recessive pattern of inheritance. This genetic disorder is one of the major public health problems and the most common one in the countries of Europe and North America, with frequencies as high as one in every 2,500 births. This disorder is provoked by mutations that affect the gene
Key words

- Gene mutations

- Amazon region

- Belém

- $\Delta$ F508 gene

- G551D gene
- Cystic fibrosis coding for the $\mathrm{CF}$ transmembrane regulation (CFTR) protein, which results in a defective flow of $\mathrm{Cl}^{-}$and $\mathrm{Na}^{+}$ions, and high concentrations of these ions in sweat (1-4).

$\Delta \mathrm{F} 508$ is the most common CF mutation $(66 \%)$ in the worldwide populations studied to date, although other mutations such as G542X (2.4\%), G551D (1.6\%), N1303K 
(1.3\%), and W1282X (1.2\%) (5-13) may be relatively frequent depending on the ethnic origin of the population.

Brazil, a country of continental dimensions, presents a special situation for studies of CF mutation frequencies. Studies carried out in five States in the South and Southeast regions of Brazil found a mean estimated prevalence for $\mathrm{CF}$ of about 1:9,600 births (5). In Rio Grande do Sul State, we observed the highest frequencies, ranging from 1:1,600 births to $1: 6,700$ births (similar to the majority of European populations). This implies that one in every 20 inhabitants of this state is heterozygous for an altered CF gene, and that mother and father are both heterozygous in one in every 400 child-bearing couples (5).

A study conducted in the Southeastern Brazilian State of Rio de Janeiro (6) found a reduced frequency of $\Delta \mathrm{F} 508(30.68 \%)$ in comparison with worldwide rates and those recorded in other populations from South and Southeast Brazil (Table 1).

Several studies on the prevalence of CF mutations have been reported in Brazil (Table 1). However, most of them were conducted in Southern States, and thus may not provide a reliable countrywide overview of the fre-

Table 1. The four most prevalent cystic fibrosis mutations in Brazil.

\begin{tabular}{|c|c|c|c|c|c|c|}
\hline \multirow[t]{2}{*}{ Region } & \multirow[t]{2}{*}{ Number of alleles } & \multicolumn{4}{|c|}{ Mutations (\%) } & \multirow[t]{2}{*}{ Reference } \\
\hline & & $\Delta \mathrm{F} 508$ & G542X & G551D & R553X & \\
\hline \multicolumn{7}{|l|}{ South } \\
\hline Rio Grande do Sul & 106 & 49.1 & 2.8 & 0 & 0 & 5 \\
\hline Rio Grande do Sul & 154 & 48.7 & 3.2 & 0 & 0.7 & 12 \\
\hline Santa Catarina & 58 & 55.2 & 3.5 & 0 & 0 & 5 \\
\hline Santa Catarina & 48 & 27 & 0 & 0 & 0 & 9 \\
\hline Paraná & 100 & 39 & 9 & 0 & 2 & 5 \\
\hline \multicolumn{7}{|l|}{ Southeast } \\
\hline São Paulo & 110 & 52.7 & 10 & 0.9 & 2.7 & 5 \\
\hline Rio de Janeiro & 88 & 30.7 & 2.3 & 1.1 & 0 & 6 \\
\hline Rio de Janeiro & 148 & 25.7 & 0 & 0 & 0 & 7 \\
\hline Rio de Janeiro & 34 & 35.3 & - & - & - & 9 \\
\hline Minas Gerais & 62 & 32.6 & 4.2 & 0 & 0 & 5 \\
\hline \multicolumn{7}{|l|}{ North } \\
\hline Belém & 66 & 22.7 & 0 & 3 & 0 & $\begin{array}{l}\text { Present } \\
\text { study }\end{array}$ \\
\hline
\end{tabular}

quency of CF mutations. In addition, most of these studies focused on mutations that are common in European populations but are usually rare in other ethnic groups. A study conducted by Rabbin-Bortolini et al. (8) about CF in São Paulo State demonstrated the presence of the G542X, N1303K and W1282X mutations, with frequencies of 8.35, 1.6 and $0.8 \%$, respectively. Cabello et al. (7) first reported two patients from the city of Rio de Janeiro carrying the G542X mutation and five other patients carrying splicing mutations $3120+1 \mathrm{G} \rightarrow \mathrm{A}$.

The wide spectrum of CF mutations (more than 900 already described) and the heterogeneous ethnic origin of the Brazilian population are important factors that must be considered to draw a broader map of this disease in the Brazilian territory. Thus, the main objective of the present study was to investigate the four most frequent CF mutations ( $\triangle \mathrm{F} 508$, G542X, G551D, and R553X) in a sample of patients with an established clinical diagnosis of $\mathrm{CF}$ in the North region of Brazil.

The sample analyzed consisted of 33 patients with a clinical diagnosis of $\mathrm{CF}$ born in the State of Pará and followed at the University Hospital João de Barros Barreto, Belém, PA, Brazil. The main clinical symptoms were: chronic asthma, repeated bronchopneumonia and destructive airway disease (respiratory symptoms), chronic diarrhea, steatorrhea and meconial ileum (digestive symptoms), and disorders of nutritional status. During this study, the two homozygous patients for the $\Delta \mathrm{F} 508$ mutation died of chronic respiratory failure resulting from secondary bacterial infection. The CF diagnosis was performed by a multidisciplinary team from the University Hospital João de Barros Barreto and was based on both abnormally elevated sweat electrolyte concentrations (i.e., two results $>60 \mathrm{mEq} / \mathrm{l}$ ) and typical clinical features related to $\mathrm{CF}$.

The Ethics Committee of the Federal University of Hospital João de Barros Barreto 
approved this research. Formal consent was obtained from all patients or from persons responsible for them.

Blood samples $(10 \mathrm{ml})$ were collected into tubes containing EDTA and genomic DNA was extracted using the phenol-chloroform method (14). The four mutations $(\Delta \mathrm{F} 508, \mathrm{G} 542 \mathrm{X}, \mathrm{G} 551 \mathrm{D}$, and R553X) were amplified using primers and conditions described below. We used two final PCR volumes $(25$ and $50 \mu \mathrm{l})$ and the amplification was carried out with an MJ Research PTC 100 (Waltham, MA, USA) thermocycler. The volume $25 \mu \mathrm{l}$ was used to observe the region of $98 \mathrm{bp}$ (exon 10), where we could verify the 3-bp deletion that constitutes the $\Delta \mathrm{F} 508$ mutation with $95 \mathrm{bp}$, amplified specific primers [5'-GTT TTC CTG GAT TAT GCC TGG CAC-3' (forward) and 5'-GTT GGC ATG CTT TGA TGA CGC TTC-3' (reverse)]. The volume $50 \mu 1$ was used to observe the G542X, G551D and R553X mutations (exon 11). These mutations were amplified using only one pair of primers [5'-CAG AGA AAG ACA ATA TAG TTC C-3' (forward) and 5'AAA TGC TTG CTA GAC CAA T-3' (reverse)]. A region of 114 bp was amplified and then three mutations were investigated: G542X, G551D and R553X. After the PCR, each mutation was submitted to an RFLP technique using $10 \mu \mathrm{l}$ of the $\mathrm{PCR}$ product for each one of the mutations, added to the specific endonuclease $(15,16)$. In a general way, the normal individuals present the restriction site, represented by the plus signal $(+)$, while the affected individuals do not present the restriction site and are represented by the minus signal (-). Thus, the band pattern observed is: i) normal individuals $=$ two bands $(+/+)$; ii) affected individuals who do not digest and present a single band (-/-), and iii) heterozygote individuals who present a three- band pattern or (+/-). The mutation G542X made use of the endonuclease $B s t N I$. For the individuals who presented the pattern $(+/+)$, which indicates absence of the mutation G542X, the investi- gation of a second restriction site was made for the endonuclease HincII (G551D). For the individuals who presented the pattern $(+/$ + ), or else, absence of the mutation G551D, the investigation of the mutation R553X was also held. At last, for the previous individuals, an investigation for the mutation R553X was made, using endonuclease $\mathrm{MboI}$.

The digestion products were analyzed by polyacrylamide gel electrophoresis and stained with $\mathrm{AgNO}_{3}$. The $\Delta \mathrm{F} 508$ mutation was observed by $7 \%$ polyacrylamide gel electrophoresis (Figure 1). The analysis of the G542X, G551D and R553X mutations were observed by $9 \%$ polyacrylamide gel electrophoresis.

In the initial sample of 33 patients who presented clinical and laboratory symptoms indicative of $\mathrm{CF}$, we observed only 17 alleles with mutations related to the $\mathrm{CF}$ gene. The mean age at genetic diagnosis of $\mathrm{CF}$ was 10 years and the mean age at clinical diagnosis was 7.3 years. The birthplaces showed a broad geographic distribution by micro-region in the State of Pará.

Two mutations were detected among the patients, $\Delta \mathrm{F} 508$ and G551D, with frequencies of $22.7 \%$ (15/66 chromosomes) and 3\% (2/66 chromosomes), respectively (Table 1). Fifteen chromosomes presented the $\Delta \mathrm{F} 508$ mutation and two individuals were homozygous $(\Delta \mathrm{F} 508 / \Delta \mathrm{F} 508)$, whereas the remaining individuals were heterozygous (Figure 1). In most cases the second allele was not identified $(\Delta \mathrm{F} 508 /$ ?). Only one sample cor-

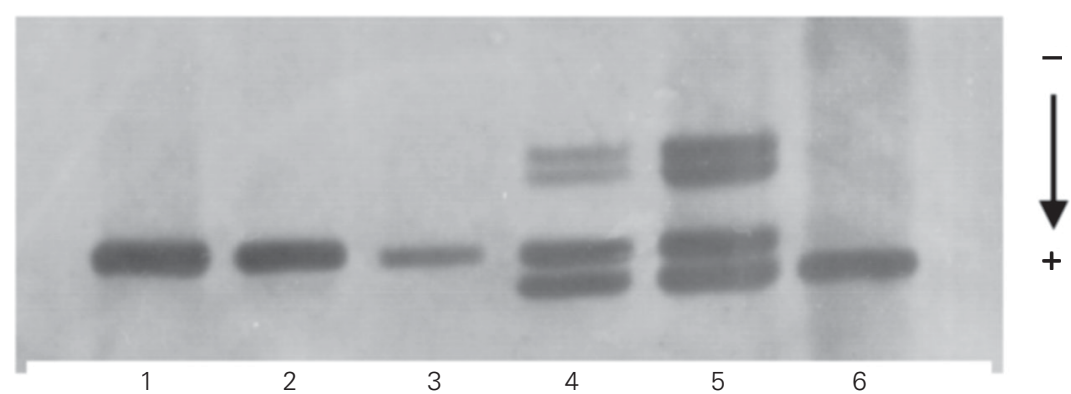

Figure 1. Analysis of the $\Delta \mathrm{F} 508$ mutation in $7 \%$ polyacrylamide gel stained with $\mathrm{AgNO}_{3}$. Individuals 1, 2 and 3 are normal considering the mutation $\Delta \mathrm{F} 508$; individuals 4 and 5 are heterozygotes, and individual 6 presents deletion $\Delta$ F508 (affected). 
responded to the genotype $\Delta$ F508/G551D. The other sample with the G551D mutation was also heterozygous but, once again, it was not possible to identify the second allele.

The $\Delta \mathrm{F} 508$ mutation was the most frequent mutation causing $\mathrm{CF}$ in the patients studied, in agreement with worldwide reports. However, the frequency of this mutation was lower $(22.7 \%)$ than the mean frequencies recorded in Europe (66\%) or other regions of Brazil. Previous studies have reported frequencies of the $\Delta \mathrm{F} 508$ mutation ranging from $25.7 \%$ in Rio de Janeiro State (Southeast of Brazil) and 55\% in Santa Catarina State (South of Brazil) (see Table 1).

We suggest that the low frequency found in the present study may be related to the distinct process of formation of the Brazilian Amazon population. Santos and Guerreiro (17) investigated 13 classic genetic systems in 5,417 members of 11 admixed Amazonian populations (characterized by the contribution of Caucasian + Amerindian + African) and demonstrated that the contribution of Amerindians (41\%) was much greater than the contribution of the African component $(12 \%)$ and smaller than the Caucasian contribution (47\%). This degree of admixture is an important consideration, given that the $\Delta \mathrm{F} 508$ mutation emerged originally in Europe 52,000 years ago, thus being considered a genetic marker of European descent (18). It seems likely that the original mean frequency of the $\Delta \mathrm{F} 508$ mutation $(66 \%)$ detected in European populations might have been diluted considerably during the intense ethnic mixing that took place during the formation of the current Amazonian populations. There is also the possibility that other as yet unidentified mutations related to Afrodescendants and Amerindians account for this disease in this region or, alternatively, the sample was small.

Cabello et al. (7) first reported a splicing mutation $3120+1 \mathrm{G} \rightarrow \mathrm{A}$ (intron 16) in five Brazilian CF patients from Rio de Janeiro. This mutation was first identified in three Afro-American subjects (12.2\%) (19), but was also identified in another population of sub-Saharan Africa (25\%) and among Greeks $(0.6 \%)$. However, in contrast to the estimated admixture for the Amazon region, the genetic proportion of ethnic admixture $(\mathrm{Eu}-$ ropeans, Africans and Amerindians) in Rio de Janeiro was 40, 52 and $8 \%$, respectively (20). Thus, we observed an inverted pattern regarding the African and Amerindian contribution in the two States.

In conclusion, molecular diagnosis is a helpful additional tool for the diagnosis and treatment of CF patients. Nevertheless, larger numbers of analyses regarding the distribution of different mutations are needed. The CF mutations detected here are consistent with the ethnic heterogeneity of the Brazilian population.

\section{References}

1. Kerem BS, Rommens JM, Buchanan JA, Markiewicz D, Cox TIC, Chakravati A, Buchwald M \& Tsui LC (1989). Identification of the cystic fibrosis gene: genetic analysis. Science, 245: 1073-1080.

2. Rommens JM, lannuzzi MC, Kerem BS et al. (1989). Identification of the cystic fibrosis gene: chromosome walking and jumping. Science, 245: 1059-1065.

3. Riordan JR, Rommens JM, Kerem BS et al. (1989). Identification of the cystic fibrosis gene: cloning and characterization of the complementary DNA. Science, 245: 1066-1073.

4. Welsh MJ, Ranzey BW, Accurso F \& Cutting GR (2001). Cystic fibrosis. In: Scriver CR, Beaudet AL, Valle D \& Sly WS (Editors), The
Metabolic and Molecular Bases of Inherited Disease. 8th edn. McGraw-Hill, New York, 5121-5173.

5. Raskin S \& Fauez FR (2001). Aspectos genéticos da fibrose cística. In: Carakushansky G (Editor), Doenças Genéticas em Pediatria. Guanabara Koogan, São Paulo, SP, Brazil.

6. Cabello GM, Moreira AF, Horovitz D, Correia P, Santa Rosa A, Llerena Jr J, Greg J, Grody WW \& Degrave WW (1999). Cystic fibrosis: low frequency of the DF508 mutation in 2 population samples from Rio de Janeiro, Brazil. Human Biology, 71: 189-196.

7. Cabello GM, Cabello EH, Fernande O \& Harris A (2001). The $3120+1 \mathrm{G} \rightarrow \mathrm{A}$ splicing mutation in CFTR is common in Brazilian 
cystic fibrosis patients. Human Biology, 73: 403-409.

8. Rabbin-Bortolini E, Bernardino ALF, Lopes AL, Ferri AS, PassosBueno MR \& Zatz M (1998). Sweat electrolyte and cystic fibrosis mutation analysis allows early diagnosis in Brazilian children with clinical signs compatible with cystic fibrosis. American Journal of Medical Genetics, 76: 288-290.

9. Raskin S, Phillips JA, Kaplan G et al. (1999). Geographic heterogeneity of 4 common worldwide cystic fibrosis non-DF508 mutations in Brazil. Human Biology, 71: 111-121.

10. Bernardino AL, Ferri A, Passos-Bueno MR, Kim CE, Nakaie CM, Gomes CE, Damaceno N \& Zatz M (2000). Molecular analysis in Brazilian cystic fibrosis patients reveals five novel mutations. Genetic Testing, 4: 69-74.

11. Colonelli GB (1999). Fibrose cística: estudo da mutação $\Delta$ F508 e dos marcadores genéticos XV2C e Km19 em afetados e na população de Belém, PA. Master's thesis, Departamento de Patologia, Centro de Ciências Biológicas, Universidade Federal do Pará, Belém, PA, Brazil.

12. Streit $C$, Burlamaque-Neto AC, Silva FE, Giugliani R \& Pereira MLS (2003). CFTR gene: molecular analysis in patients from South Brazil. Molecular Genetics and Metabolism, 78: 259-264.

13. Visich A, Zielenski J, Castaños C, Diez G, Grenoville M, Segel E, Barreiro C, Tsui LC \& Chertkoff L (2002). Complete screening of the CFTR gene in Argentine cystic fibrosis patients. Clinical Genetics, 61: $207-213$
14. Sambrook J, Fritsch EF \& Maniatis T (1989). Molecular Cloning: $A$ Laboratory Manual. 2nd edn. Cold Spring Harbor Laboratory Press, Cold Spring Harbor, NY, USA.

15. Cutting GR, Kash LM, Rosenstein BJ, Tsui LC, Kazazian HH \& Antonarakis SE (1990). Two patients with cystic fibrosis, nonsense mutation in each cystic fibrosis gene, and mild pulmonary disease. New England Journal of Medicine, 323: 1685-1689.

16. Cutting GR, Kash LM, Rosenstein BJ, Zielenski J, Tsui LC, Antonarakis SE \& Kazazian HH (1990). A cluster of cystic fibrosis mutations in the first nucleotide-binding fold of the cystic fibrosis conductance regulator protein. Nature, 346: 366-369.

17. Santos S \& Guerreiro JF (1995). The indigenous contribution to the formation of the population of the Brazilian Amazon Region. Revista Brasileira de Genética, 18: 311-315.

18. Dawson KP \& Frossard PM (2000). The geographic distribution of cystic fibrosis mutations gives clues about population origins. European Journal of Pediatrics, 159: 496-499.

19. Macek M, Mackova A, Hamosh A et al. (1997). Identification of common cystic fibrosis mutations in African-Americans with cystic fibrosis increases the detection rate to $75 \%$. American Journal of Human Genetics, 60: 1122-1127.

20. Lopez-Camelo JS, Cabello PH \& Dutra MG (1996). A simple model for the estimation of congenital malformation frequency in racially mixed populations. Brazilian Journal of Genetics, 19: 659-663. 